\section{Review of carbon footprint assessment in textile industry}

\author{
Jin Zhang, Xiaoming Qian and Jing Feng \\ Tiangong University, Tianjin, China
}

Review of carbon footprint assessment

\begin{abstract}
Purpose - Under the global climate change, carbon footprint has become a hot issue at home and abroad. However, there is no consensus on the concept, measurement and application of carbon footprint.

Design/methodology/approach - In this paper, first, the concept and connotation of carbon footprint are reviewed; then, different methods of carbon footprint measurement are compared, and it is found that "bottom-up" life cycle assessment and "top-down" input-output analysis are applicable to different research scales.
\end{abstract}

Findings - Finally, the problems in the process of carbon footprint assessment in textile industry are analyzed and further research directions are proposed.

Originality/value - Analyzed and further research directions are proposed.

Keywords Carbon footprint, Research progress, Evaluation method

Paper type Research paper

\section{Introduction}

Under the background of the rapid development of global economy, a series of resource and environmental problems such as environmental pollution, energy shortage and ecological damage are becoming more and more prominent, especially the climate change caused by $\mathrm{CO}_{2}$ and other $\mathrm{GHG}$, which has become one of the severe challenges facing the development of human society and a hot topic in the academic research field (Geng et al., 2010). According to the fourth assessment report issued by the Intergovernmental Panel on Climate Change in 2007 , more than $90 \%$ of global climate anomalies may be caused by excessive greenhouse gases (GHG) emissions (Xin and Zhang, 2008). According to the fifth comprehensive assessment report released in 2013, the increasing impact of human beings on the climate system is clear, and various impacts have been observed on all continents of the world.

To reduce GHG emissions, the United Nations began to include carbon emissions into the discussions of the conference in the 1990s. In 1992, the United Nations Framework Convention on Climate Change was adopted at the United Nations Conference on Environment and Development. It is the first convention to control GHG in the world. In December 1997, the Kyoto agreement on climate change was discussed and formulated at three meetings of the participating countries of the United Nations Framework Convention on Climate Change. Its goal is to stabilize the GHG content of the atmosphere in an appropriate way, and then prevent severe climate change from causing harm to human

(C) Jin Zhang, Xiaoming Qian and Jing Feng. Published in Ecofeminism and Climate Change. Published by Emerald Publishing Limited. This article is published under the Creative Commons Attribution (CC BY 4.0) licence. Anyone may reproduce, distribute, translate and create derivative works of this article (for both commercial and non-commercial purposes), subject to full attribution to the original publication and authors. The full terms of this licence may be seen at http:// creativecommons.org/licences/by/4.0/legalcode

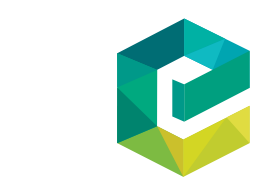

Received 4 January 2020 Revised 25 February 2020 Accepted 2 March 2020

Ecofeminism and Climate Change Vol. 1 No. 1, 2020 Emerald Publishing Limited p-ISSN: 2633-4062 e-ISSN: $2633-4070$ DOI 10.1108/EFCC-03-2020-0006 
EFCC 1,1

beings. The Kyoto Protocol requires developed countries to undertake the obligation of reducing carbon emissions from 2005, and developing countries to undertake the obligation of reducing carbon emissions from 2012, which is the first time in human history to limit $\mathrm{GHG}$ emissions in the form of regulations.

GHG that cause global warming mainly include water vapor $\left(\mathrm{H}_{2} \mathrm{O}\right)$, carbon dioxide $\left(\mathrm{CO}_{2}\right)$, methane $\left(\mathrm{CH}_{4}\right)$, nitrous oxide $\left(\mathrm{N}_{2} \mathrm{O}\right)$, ozone $\left(\mathrm{O}_{3}\right)$, freon $(\mathrm{CFCs})$, etc. $\mathrm{CO}_{2}$ is the largest source of $\mathrm{GHG}$, and it has become a global consensus to control the concentration of $\mathrm{CO}_{2}$ in the atmosphere within a suitable range (Ding et al., 2009). Therefore, in the context of increasingly severe global warming, the concept of carbon footprint was first proposed by British scholars, which refers to a newly developed indicator for measuring the environmental impact of $\mathrm{CO}_{2}$ emissions generated by institutions or individuals because of daily energy consumption (Luo et al., 2010).

To implement the work of energy conservation and emission reduction, countries around the world have formulated a series of relevant policies. The UK is the first country to legislate and publish the carbon budget for GHG emission reduction targets. The European Union has formulated a package of energy plan, energy technology strategic plan (Wang, 2015). On this basis, carbon footprint standards such as PAS 2050, product and supply chain GHG protocol and ISO 14067 came into being to standardize the carbon footprint assessment process. In 2009, China proposed that $\mathrm{CO}_{2}$ emissions per unit of GDP will be reduced by 40-50\% compared with 2005 by 2020 (Liu, 2010). In August 2010, China's National Development and Reform Commission issued an official document and carried out the pilot work of low-carbon provinces and cities.

It can be seen from the above that energy conservation and emission reduction and industrial optimization and upgrading are the inevitable trend of development, and energy conservation and emission reduction involve all industries. Textile industry is closely related to GHG emissions. It plays different market roles in different stages of the whole life cycle, including cotton planting and cultivation, textile material research and development, textile material processing industry, textile wholesale industry and textile sales industry.

At the same time, the textile industry, as a dominant export industry in China, and as an important processing and production field, is facing increasingly severe environmental problems; the low-carbon environmental protection of the whole industry has a significant impact on climate change. Therefore, it is necessary to evaluate the carbon footprint of the whole life cycle of the textile industry and the carbon emission reduction of China's textile industry, so as to improve the environmental value of products, and then put forward suggestions for energy conservation and emission reduction to achieve sustainable development.

Therefore, this study can identify the connotation of the whole life cycle of the textile industry and evaluate the carbon emission in the whole life cycle of the textile industry to provide the accounting basis for the carbon footprint of the textile industry and propose the improvement measures to reduce the carbon footprint of the textile industry.

\section{Definition of carbon footprint}

The term of carbon footprint was first used in the concept of ecological footprint proposed by Williams Reese and other scholars. Ecological footprint is a biologically productive regional space that can continuously provide resources or absorb waste areas, which means to maintain the survival of a person, region, country or the world, or to accommodate the waste discharged by human beings, with biological productivity of the area (Finkbeiner, 2009). Carbon footprints usually account for the direct and indirect six GHG emitted because 
of production and activities in a certain period of time, which is usually expressed as $\mathrm{CO}_{2}$ equivalent. Carbon consumption is large and $\mathrm{CO}_{2}$ emissions are increasing.

At present, there is no consensus on the concept and connotation of carbon footprint in academic circles. There are three mainstream views: first, carbon footprint is the $\mathrm{CO}_{2}$ emissions generated by burning fossil fuels in the process of human activities; second, carbon footprint is defined as the $\mathrm{CO}_{2}$ conversion of $\mathrm{CO}_{2}$ and other $\mathrm{GHG}$ emitted by products in the whole life cycle of raw material acquisition, production, distribution, use and recovery; and third, the focus of the concept of carbon footprint is to measure the impact of human activities on climate change based on direct and indirect $\mathrm{CO}_{2}$ conversion.

Through the retrieval of the life cycle literature of the textile industry, it is found that scholars have little research on the life cycle of the textile industry, and only a few researchers have studied the life cycle of textile clothing and regional textile. However, the research on carbon footprint evaluation of textile industry is relatively lacking. According to the data, the energy consumption of the whole production process of the textile industry, that is, the life cycle of the textile industry (from fiber processing to clothing products), is about 4.84 tons of standard coal/ton of fiber, accounting for about $4.4 \%$ of the total energy consumption of the national industry (Li et al., 2011). Facing the increasing global warming, the textile industry urgently needs to control the low-level expansion of high energy consumption and high pollution industries, eliminate backward production capacity, adjust the industrial structure and take the road of sustainable development. Therefore, the research on the evaluation of carbon footprint of a textile industry based on the whole life cycle has certain significance for the development of energy conservation and emission reduction.

\section{Evaluation method of carbon footprint for textile industry}

Through consulting the literature on the evaluation of carbon footprint in the textile industry, it is concluded that the evaluation methods of carbon footprint and carbon footprint in the textile industry mainly include ecological cycle evaluation method, inputoutput analysis method and mixed life cycle evaluation method.

First, the input-output model is an economic quantitative method to study the interdependence between various parts of the economic system, which runs in the whole industry cycle. Christopher analyzed the impact of international trade on the carbon footprint of American households by using the method of inter-regional input-output analysis model and life cycle assessment (LCA) through the investigation of consumption and expenditure (Christopher and Weber, 2008). Druckman and Jackson (2009) then further expanded the research to the multi region input-output model to make a comparative analysis of different time scales and different families (Druckman and Jackson, 2009).

The whole life cycle of the textile industry is very long. Based on the activities of the textile industry, it is defined as three stages: the first stage is the agricultural stage, i.e. the cultivation of textile raw materials; the second stage is the industrial stage, i.e. the production and processing of textiles; and the third stage is the sales stage, i.e. the transportation and distribution of textiles. The input-output method is used to analyze the carbon emissions generated by the economic activities of the textile industry in different stages, which are not only targeted, but also can avoid the truncation error. At the same time, the input-output analysis table is established, which can be used to calculate the carbon footprint of the textile industry easily and quickly.

Then, LCA is a typical system analysis method, which is opposite to input-output analysis and a bottom-up carbon footprint calculation method. The evaluation steps of LCA method for carbon footprint include the following steps: the establishment of product

\section{Review of carbon \\ footprint \\ assessment}


EFCC 1,1

manufacturing flow chart, determination of system boundary, collection of data, calculation of carbon footprint and test of results. To standardize and promote the application of carbon footprint accounting in enterprises, the International Organization for Standardization, the British Standards Institute and the World Resources Institute have developed or are developing standards for carbon footprint accounting of organizations and products (Ren, 2011).

Finally, hybrid economic input-output LCA is gradually developed on the basis of LCA. This method was proposed by Bullard after the first oil crisis in the 1970s and mainly used for energy input-output analysis (Bullard et al., 1976). The Stockholm Environmental Research Institute calculated the carbon footprint of British schools by combining process analysis and input-output analysis. On the basis of input-output analysis, supplemented by process analysis based on the detailed data. This hybrid method can integrate the advantages of process analysis and input-output analysis. It not only has the systematic advantages of top-down method, but also has the flexibility of bottom-up method. It also can get more objective and systematic evaluation results.

On the basis of reading a lot of domestic and foreign research on carbon footprint of textile industry, summarizing the previous research results, it is found that most of the research on carbon footprint of textile industry is focused on the research of textile processing, and there is little research on textile industry to analyze its carbon footprint in the whole life cycle. LCA theory is the current research hotspot, and the relevant organizations in the world generally formulate carbon emission calculation standards based on LCA theory. Through the analysis and comparison of the above three carbon emission calculation methods, combined with the research object of textile industry, it is suggested to select the LCA method to calculate the carbon emission of products.

\section{Analysis of problems in carbon footprint research of textile industry}

4.1 Uncertainty and incompatibility of carbon footprint accounting results of textile products The whole life chain from agriculture to industry, to the stage of product use and even to the stage of final product abandonment is long, and the data quality of the final product carbon footprint is difficult to guarantee. The accounting process, distribution method and trade-off principle of textile carbon footprint of different researchers are not explained in detail, which makes it impossible to trace the rationality of their accounting results. Based on different accounting models and accounting boundaries, the accounting results of carbon footprint of the same textile products are even very different, which makes it impossible to compare the differences of carbon footprint of the same textile products horizontally.

\subsection{Stage division and origin analysis of carbon footprint of textile products}

At present, carbon footprint research theory has been applied in many fields and industries. Domestic research mainly focuses on regional, enterprise, industry and other directions, and there is not much research in the field of textile industry. When analyzing the carbon footprint of textile industry, the relevant literature uses the life cycle theory to roughly estimate its carbon emissions in the design, production, sales and recovery stages, without a detailed analysis of the sources of its carbon footprint in the life cycle and the definition of its carbon footprint accounting boundary.

\subsection{Lack of carbon footprint assessment of textile products}

Carbon footprint can be a driving indicator of carbon emission, and sustainable development of environment and social economy depends on whether it can reflect the potential impact of carbon emission on environment and economic development. However, 
the existing carbon footprint accounting methods do not follow the research steps to evaluate the impact of carbon footprint results. Therefore, it can only reflect the GHG emissions of production activities, but not have to reference significance for people to formulate the sustainable development strategy of environment and economy. In addition, comparing the carbon footprints of the same products in different regions can not only compare the carbon footprints, but also quantify their impact on the environment and social development of the corresponding regions, and then formulate corresponding regional measures to reduce production energy consumption.

\section{Research ideas on carbon footprint of textile industry}

Based on the existing analytical methods and research results of carbon footprint in textile industry and the existing problems, this paper will suggest the carbon footprint in textile industry with life cycle theory as the support and input-output analysis as the method.

\subsection{Establish a common life cycle assessment-based carbon footprint accounting method for textile industry}

The research shall refine the accounting method of textile products and improve the accuracy of the list, make the accounting process traceable and compare the industrial carbon footprint of the same textile product.

\subsection{Analyze the time and space distribution of textile industry in the whole life cycle}

Referring to the existing industry carbon footprint accounting standards, this paper elaborates the performance behavior and space-time trajectory of the textile industry in different stages of the whole life cycle, extends the research of the textile industry carbon footprint to the time dimension and analyzes its space-time distribution in the whole life cycle.

\subsection{Adding carbon footprint impact assessment to carbon footprint accounting}

To quantify the impact of carbon emissions on the environment and social development, the carbon footprint impact assessment is added to the carbon footprint accounting, which reflects the impact of carbon emissions on the environment, social and economic sustainable development, facilitates the comparison between different regional products and provides the basis for the government or enterprises to formulate the corresponding regional emission reduction policies.

\section{References}

Bullard, C.W., Penner, P.S. and Pilati, D.A. (1976), "Net energy analysis: handbook for combining process and input-output analysis", Resources and Energy, Vol. 1 No. 3, pp. 267-313.

Christopher, L. and Weber, H.S. (2008), "Quantifying the global and distributional aspects of American household carbon fooprint”, Ecological Economics, Vol. 66 Nos 2/3, pp. 379-391.

Ding, Z.L., Duan, X.N., Ge, Q.S., et al. (2009), "Evaluation of international greenhouse gas emission reduction programs and discussion on China's long-term emission rights", China Science, Vol. 39 No. 12, pp. 1659-1671.

Druckman, A. and Jackson, T. (2009), "The carbon footprint of UK households 1990-2004: a socioeconomically disaggregated, quasi-multi-regional input-output model”, Ecological Economics, Vol. 68 No. 7, pp. 2066-2077. 
EFCC

1,1

56

Finkbeiner, M. (2009), "Carbon footprinting - opportunities and threats", The International Journal of Life Cycle Assessment, Vol. 14 No. 2, pp. 91-94.

Geng, Y., Dong, H.J., Xi, F.M., et al. (2010), "A review of carbon footprint research in response to climate change", China Population, Resources and Environment, Vol. 20 No. 10, pp. 6-12.

Li, R., Wu, D.D., Jiang, H. and Ding, X.J. (2011), "Carbon footprint and its calculation in dyeing and finishing", Printing and Dyeing, Vol. 37 No. 18, pp. 40-43.

Liu, Y.W. (2010), "Analysis on the development of coal chemical industry during the 12th five year plan”, Chemical Industry, Vol. 28 No. 10, pp. 8-10.

Luo, Y.K., Zhou, L.M. and Zhu, M.Y. (2010), "Carbon footprint analysis", Journal of Agricultural and Forestry Economic Management, Vol. 9 No. 2, pp. 123-127.

Ren, L.J. (2011), Research on Life Cycle Assessment Method and Life Cycle Assessment of Typical Paper Products, Beijing University of technology.

Wang, S.S. (2015), Research and Software Development of Modular Accounting Method for Carbon Footprint of Textile Products Industry, Donghua University.

Xin, Z.P. and Zhang, Y.T. (2008), "Low carbon economy and low carbon city", Urban Development Research, Vol. 15 No. 4, pp. 98-102.

\section{Corresponding author}

Jing Feng can be contacted at: jingfengwater@126.com

For instructions on how to order reprints of this article, please visit our website: 